\title{
Research in the field of using of ash from the incineration of sewage sludge, treated with mineral binders, for forest road construction
}

\author{
Oksana Zubova ${ }^{1, *}$, Vadim Siletskiy ${ }^{1}$, Daniil $\mathrm{Kulik}^{1}$, Taras Kovalenko ${ }^{1}$, and Mihail \\ Naskovets ${ }^{2}$. \\ ${ }^{1}$ Saint-Petersburg State Forest Technical University named after S.M. Kirov, Institute per., 5194021 \\ St. Petersburg, Russian Federation \\ ${ }^{2}$ Belarusian State Technological University, Sverdlova str., 13a, 220006 Minsk, Belarus
}

\begin{abstract}
The purpose of the study is to obtain a durable and cheap roadbuilding material based on ash, reinforced with mineral astringent. Within the framework of the research, the optimal dosages of binders were searched for, the characteristics of the strength of mixture of ash with sludge and ash with cement were also determined. A comparative analysis of the economic efficiency between using a mixture of ash from the incineration of sewage sludge, reinforced with nepheline sludge, and traditional road building materials was carried out. The results of the study of mixtures of ash with mineral binders, such as nepheline sludge and cement, show that the obtained materials have high strength indicators and high indicators of the modulus of elasticity. They can be attributed to strength grades from M20 to M100. The developed building material (ash mixed with binders (nepheline sludge, cement)) could replace a similar building material in the technology of road construction, because if this mixture is taken in optimal dosages, it will be more profitable in the process of use, both from the point of physical and mechanical views, and point of view of economic indicators.
\end{abstract}

\section{Introduction}

The dynamics of growth in industrial production is increasing every year, this fact requires an increase in the volume of resources, including forest products. A large amount of forest is concentrated in Russia, but its remoteness from the main infrastructure facilities requires the intensive development of a network of forest roads, and, as a result, a significant increase in the volume of road-building materials is also need. This is possible due to the expansion of the range of materials, including through the use of waste. The use of industrial waste exhibiting surface activity or binding properties is one of the economically viable options for expanding the resource base for the road construction industry.

The study of expanding the base of road building materials due to the use of a nepheline sludge was studied by V.M. Beskrovny and I.V. Meshcheryakov [1-3]. They proved that

\footnotetext{
*Corresponding author: ok_z19@mail.ru
} 
nepheline sludge exhibits high binding activity, durability and can be used in road construction outside of settlements.

Every year the problem of waste disposal is becoming increasingly important. The number of polygons is increasing, each year the area occupied by such objects is growing and this area is already reaching catastrophic proportions. The landfills of the State Unitary Enterprise "Vodokanal" of St. Petersburg are overflowed with ashes derived from the incineration of sewage sludge. Today, reducing the amount of waste contained in landfills is one of the problems, which has main importance.

According to G. Borowski's research [3], as a result of vetrification (sintering at temperatures up to $1500^{\circ} \mathrm{C}$ ) of ash from the incineration of municipal waste, the vitrification of ash with encapsulation of heavy metals is obtained. This technology is expensive, in addition, the scope of application of vetrified ash is limited. At the same time, according to studies of the interaction of ash from incineration of sewage sludge with mineral and organic binders, the level of leaching of heavy metals also remains within the permissible limits, which makes it possible to recommend this product for road construction. At the same time, the use of ash in road-building material will make it possible to dispose of large volumes of waste.

In studies by Jiang-shanLi et al. [4] the possibility of recycling ash from incineration of sewage sludge is being considered for the recovery of commercially viable components such as phosphorus, zinc, etc. However, this technology does not provide for the disposal of the remaining part of the ash contaminated with toxic substances.

O. A. Johnson et al. from Malaysia, in their review [5], also point out that ashes from incineration of sewage and other municipal waste are used as aggregate in ceramics, glass and concrete. At the same time, the intrinsic binding properties of ash and sludge have not been sufficiently investigated, which, according to research by Zubova O.V. and others [67] have some physical and chemical activity.

Portuguese researchers [8] considered the issues of encapsulating ash from wastewater incineration in bitumen-mineral mixtures, however, the aspect of leaching of harmful substances from ash was not taken into account, therefore, only technological parameters.

The use of ash derived from the incineration of sewage sludge in the construction of forest roads can reduce the cost of road pavement and increase the lifespan of forest roads, which will allow to build forest roads for small logging enterprises too. Increasing the network of forest roads will allow to harvest wood more efficient with a lower cost. Also, due to the reduced cost of forest roads, it will be possible to develop remote forest resources.

It turned out 20 years of operation of the CSA sewage sludge incineration plant on the island White In November 2017. During the operation of this unique enterprise, a wealth of experience has been accumulated. It makes possible to conclude that the production as a whole copes with the tasks of deep utilization of precipitation generated during the treatment of wastewater.

At CSA is being cleaned up to 1.5 million. $\mathrm{m} 3$ of wastewater per day, this produces up to 200 tons of dry matter of precipitation per day burned in kilns using Pyrofluid technology.

\section{The purpose and objectives of the study}

The purpose of the study is to obtain a durable and economical road-building material based on ash reinforced with a mineral binder. 


\section{Objectives of the study}

1. Search for optimal dosages of binders.

2. Determination of the strength characteristics of the obtained material.

3. Determination of the elastic modulus of the obtained material.

4. Comparative analysis of the economic efficiency of using ash mixed with nepheline sludge with traditional road-building materials.

\section{Materials and Methods}

Ash - is a fine powder of yellow-brown color. The size of the ash particles is about $1 \div$ 10-50 microns. The specific surface of the ash is about $2000-3000 \mathrm{~cm}^{2} / \mathrm{g}$. The main ash compound is $\mathrm{SiO}_{2}$, which ranges from 48 to $54 \%$ of its mass composition. However, ash has drawbacks, such as the content of heavy metals in it, which significantly limits its direct use. [1]

Nepheline sludge - a slurry-like waste generated during the production of alumina, containing $80-85 \% 2 \mathrm{CaO}-\mathrm{SiO}_{2}-\mathrm{xH} 2 \mathrm{O}$ and $2 \mathrm{CaO}-\mathrm{SiO}_{2}$; the rest of the mass is hydrates of alumina, iron, sodium and potassium sulfates, complex hydrates. Nepheline sludge contains about $80 \%$ of belite or dicalcium silicate.

Portland cement M-400. Portland cement is a hydraulic binder, which predominantly consists of calcium silicates $(70-80 \%)$. The mixture consists of components that create a structure that is $95-98 \%$ composed of mineral elements. They are in a solid state of aggregation. The bulk density is $1100-1200 \mathrm{~kg} / \mathrm{m}^{3}$. Strength established by the manufacturer is reached after $28-30$ days at $95-98 \%$.

\section{Theoretical substantiation of the use of ash from the incineration of sewage sludge and nepheline sludge in road construction}

According to exploratory studies, the ash from incineration of sewage sludge is not an active astringent, however, the presence of large amounts of $\mathrm{SiO}_{2}$ in ash (more than $50 \%$ mass) suggests the possibility of the interaction of the active part of ash with calcium components of mineral binders with the formation of strong crystalline structural components.

The active properties of fine particles are largely determined by the crystal-chemical characteristics of the mineral component and their high dispersion (that is, extremely small particle size).

Fine particles of silica and other ash minerals are highly ion-exchangeable, that is, replacing some of the ions on the surface and in the crystal lattice of particles with ions coming from the solution. The noted features of various minerals, together with their high dispersion, and therefore extremely developed surface, cause a very large adsorption capacity - the ability to actively absorb various substances and chemical elements from solutions. The interaction of fine ion-active ash particles with tricalcium silicates that are part of the mineral binder in the process of hydration contributes to a multiple increase in the strength of the material. Thus, it is necessary to combine the ash with Ca-based mineral binder, such as cement or nepheline sludge, to activate the amorphous silica contained in the ash to form strong crystalline structures.

The Department of Industrial Transport of St. Petersburg State Technical University together with the Institute of Silicate Chemistry, St. Petersburg, conducted studies on the binding activity of ash using an X-ray diffractometer DRON UM-1 [9]. An analysis of the 
X-ray diffraction patterns showed that during the hardening process, the fine component of the mixture $\left(\mathrm{SiO}_{2}\right.$, which is mainly present in the composition of the ash), enters into chemical interaction with another component of the mixture. This component is calcium hydroxide $\mathrm{Ca}(\mathrm{OH})_{2}$, which is formed as a result of the interaction of nepheline sludge or cement with water. The chemical process of interaction of the components of the mixture takes a long time. The hardening process in the studied mixtures of ash and binders is due to the formation of a cementing ligament: - due to the chemical interaction of fine-grained $\mathrm{SiO}_{2}$ (part of the ash), with calcium hydroxide $\mathrm{Ca}(\mathrm{OH})_{2}$, which leads to the formation of hydrosilicates and hydroaluminosilicate calcium and due to chemical interaction of finely dispersed (amorphous) $\mathrm{SiO}_{2}$ (part of the ash with water).

\section{Research methodology}

Processing and analysis of the results of exploratory experiments with ash treated with binders (cement and nepheline sludge) allowed us to obtain high strength properties of road-building material and a sufficiently high degree of reliability, which made it possible to develop a methodology for experimental work.

\section{Mixture preparation}

Nepheline sludge and ash are dried to air-dry state, sieved through a sieve with $5 \mathrm{~mm}$ holes. The moisture content of the material is determined by drying the weights of the material in a thermostat to the constant weigh with a temperature of $105{ }^{\circ} \mathrm{C}$. Mixing material with binders produced without moistening the material. During the process of preparing mixtures of material with cement, nepheline sludge, binders are added to the air-dry material, the mixture is stirred and watery (taking into account the moisture contained in the material) to optimum humidity. The mixture is thoroughly mixed in a laboratory paddle stirrer for 4-6 minutes.

\section{Production and storage of samples}

The optimal dosage of the main binders is determined by selection, for which about 10 test mixes are prepared, differing in the content of binders. Samples-cylinders are made from these mixtures and they are tested to determine the indicators of the physicomechanical properties of hardened materials. The minimum dosage of the binder, which provides indicators that meet the requirements of state standard 23558-94 [10], is optimal. - Samples made from different mixtures are stored in wet conditions. Samples from materials fortified with Portland cement are stored for 28 days. Samples of materials fortified nepheline sludge, stored for 90 days.

\section{Results and Discussion}

\subsection{Determination of compressive strength of samples}

The compressive strength is determined on samples subjected to full or capillary saturation. Full water saturation of samples with a height and diameter of $3.5 \mathrm{~cm}$ is produced in calm water for 3 days, on the first day the samples are immersed in water at $1 / 3$ of the height, and in the following days - completely filled with water. In order to prevent the drying of 
specimens immersed in water at $1 / 3$ of height, saturation is carried out in a bath with a water gate.

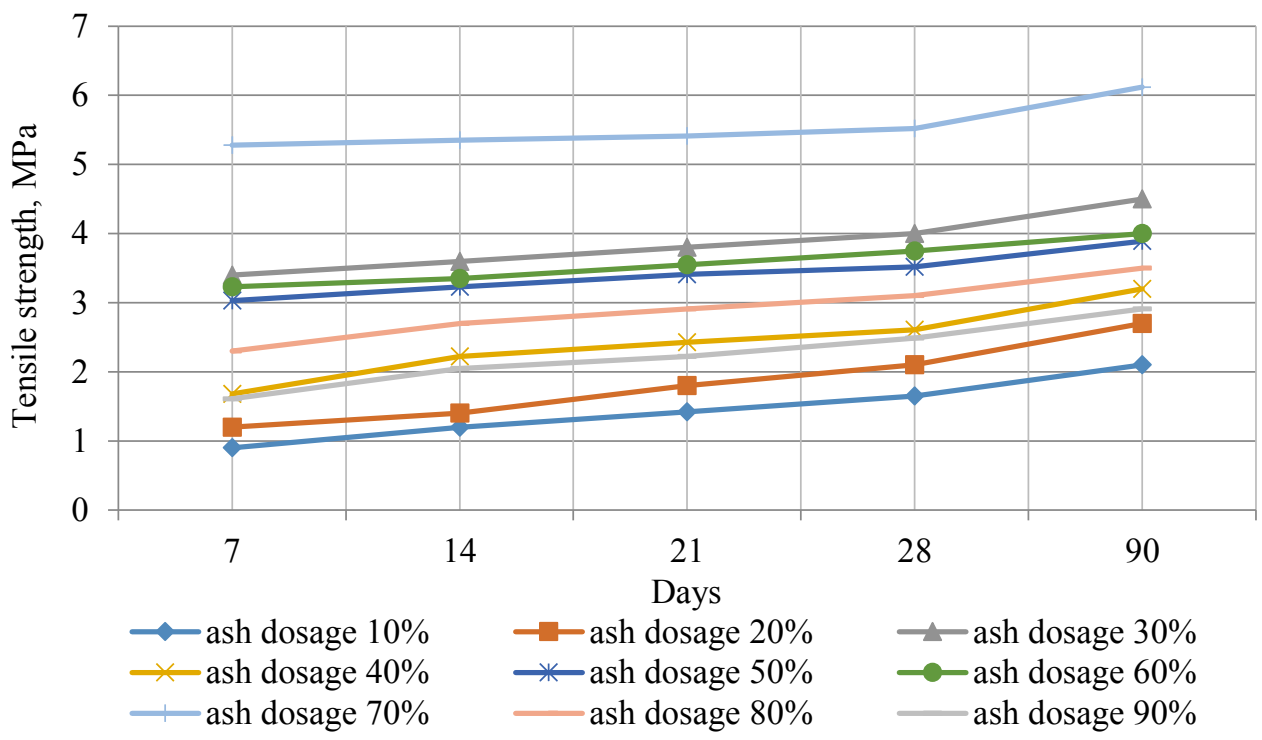

Fig. 1. Graphic dependence of the ultimate strength in compression of mixtures of nepheline sludge and ash in different ratios from the time of structure formation.

The regression equations for the experimental curves are given below:

Ash dosage $10 \%-\mathrm{R}_{\text {compr }}=0.285 \mathrm{t}+0.599 ; \mathrm{R}^{2}=0,9806$

Ash dosage $20 \%-\mathrm{R}_{\text {compr }}=0.37 \mathrm{t}+0.73 ; \mathrm{R}^{2}=0.9695$

Ash dosage $30 \%-\mathrm{R}_{\text {compr }}=0.26 \mathrm{t}+3.12 ; \mathrm{R}^{2}=0.9941$

Ash dosage $40 \%-\mathrm{R}_{\text {compr }}=0.301 \mathrm{t}+1.567 ; \mathrm{R}^{2}=0.9507$

Ash dosage $50 \%-\mathrm{R}_{\text {compr }}=0,203 \mathrm{t}+2,809 ; \mathrm{R}^{2}=0.9613$

Ash dosage $60 \%-\mathrm{R}_{\text {compr }}=0.218 \mathrm{t}+2.946 ; \mathrm{R}^{2}=0.9605$

Ash dosage $70 \%-\mathrm{R}_{\text {compr }}=0,203 \mathrm{t}+4,933 ; \mathrm{R}^{2}=0.9649$

Ash dosage $80 \%-\mathrm{R}_{\text {compr }}=0.28 \mathrm{t}+2.062 ; \mathrm{R}^{2}=0.9799$

Ash dosage $90 \%-\mathrm{R}_{\text {compr }}=0,28 \mathrm{t}+1,436 ; \mathrm{R}^{2}=0.9818$

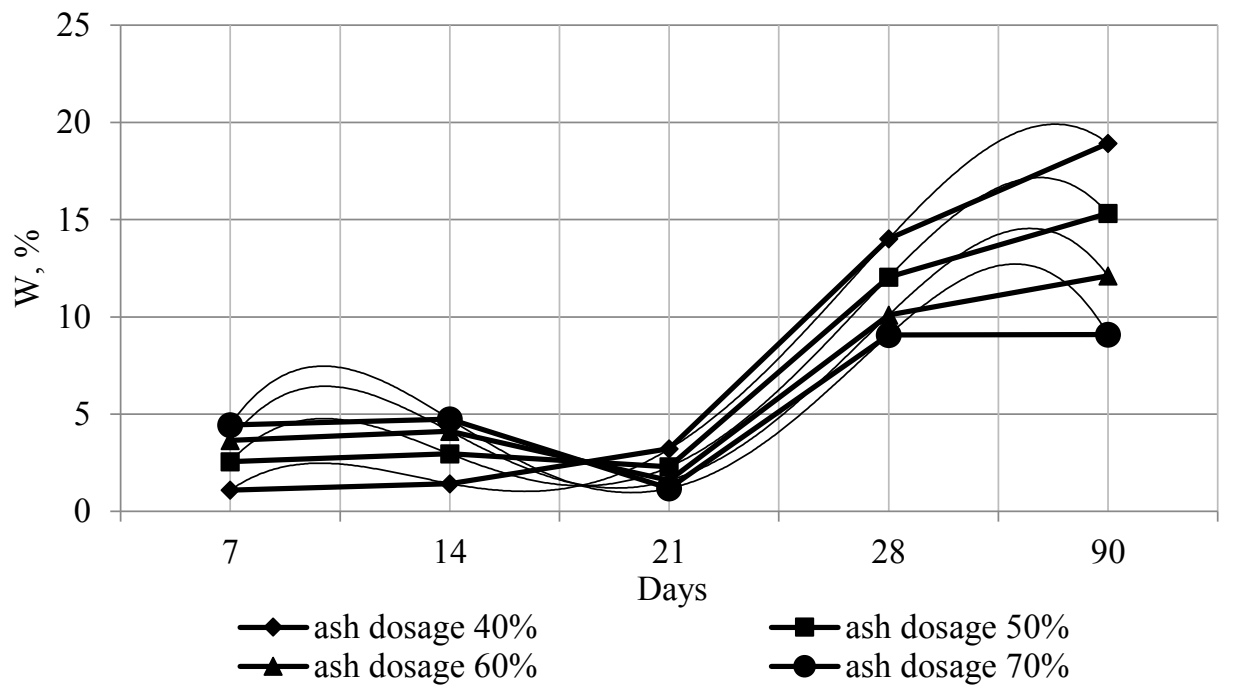


Fig. 2. Graphic dependence of water absorption of samples on the time of their structure formation

Ash dosage is $40 \%-\mathrm{W}=-0.9371 \mathrm{t} 4+10.634 \mathrm{t} 3-39.658 \mathrm{t} 2+58.931 \mathrm{t}-27.88 ; \mathrm{R}^{2}=1$

Ash dosage is $50 \%-\mathrm{W}=-1,1829 \mathrm{t} 4+13,746 \mathrm{t} 3-53,442 \mathrm{t} 2+82,259 \mathrm{t}-38.83 ; \mathrm{R}^{2}=1$

Ash dosage is $60 \%-\mathrm{W}=-1.3158 \mathrm{t} 4+15,502 \mathrm{t} 3-61,624 \mathrm{t} 2+96,578 \mathrm{t}-45.49 ; \mathrm{R}^{2}=1$

Ash dosage is $70 \%-\mathrm{W}=-1.4442 \mathrm{t} 4+16,997 \mathrm{t} 3-67,811 \mathrm{t} 2+106,42 \mathrm{t}-49,71 ; \mathrm{R}^{2}=1$

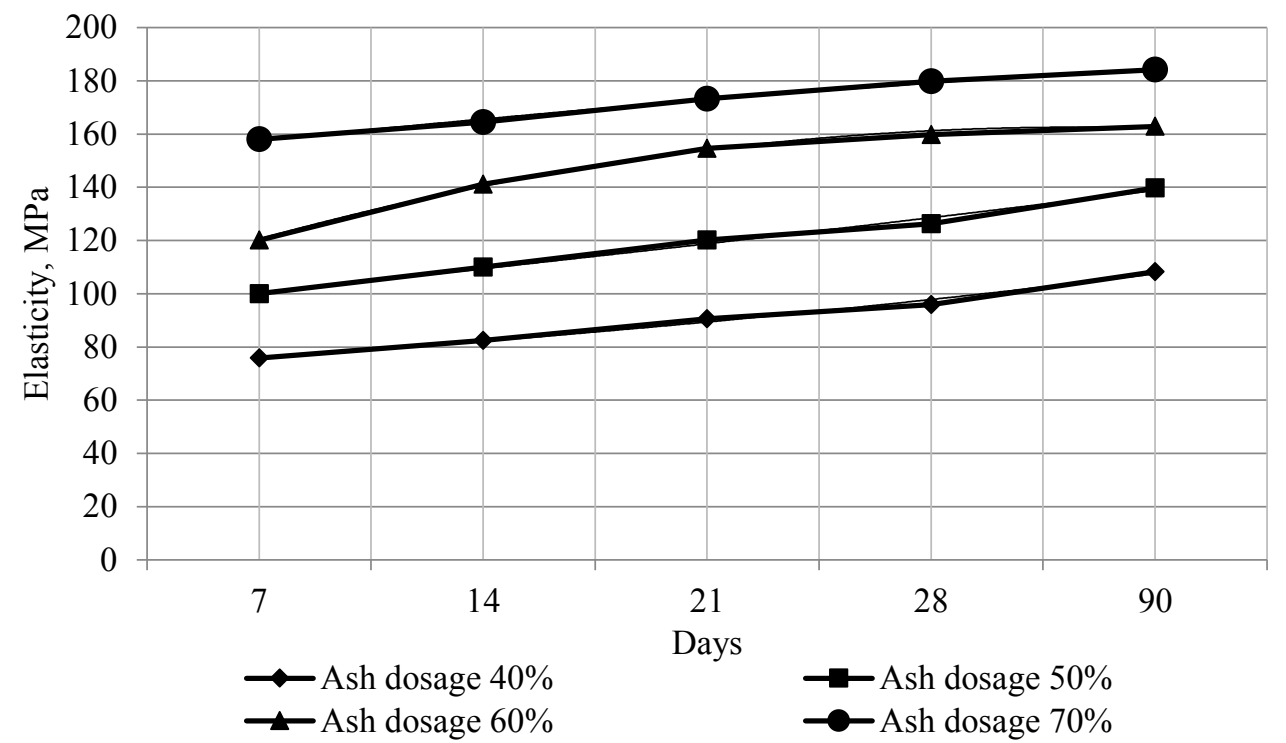

Fig. 3. Graphic dependence of the modulus of elasticity of the samples from the time of their structure formation.

The regression equation for the experimental curves is shown below:

The ash dosage is $40 \%-\mathrm{E}=0.6136 \mathrm{t} 2+4.1416 \mathrm{t}+71.438 ; \mathrm{R}^{2}=0.9899$

The ash dosage is $50 \%-\mathrm{E}=0.2193 \mathrm{t} 2+8.2613 \mathrm{t}+92.022 ; \mathrm{R}^{2}=0.991$

The ash dosage is $60 \%-\mathrm{E}=-3.1543 \mathrm{t} 2+29.324 \mathrm{t}+94.404 ; \mathrm{R}^{2}=0.9968$

The ash dosage is $70 \%-\mathrm{E}=-0.4671 \mathrm{t} 2+9.5829 \mathrm{t}+148.33 ; \mathrm{R}^{2}=0.9947$

\subsection{Analysis of the study of physical and-mechanical properties of samples of nepheline sludge mixed with ash}

1. The graphs of fig. 1 shows the dependence of the compressive strength of watersaturated samples on the ash dosage and the time of structure formation. The resulting material has a strength of from 0.9 to $6.2 \mathrm{MPa}$. On the graph, we see that the maximum strength indicators are achieved with the ratios of ash and sludge $70 \%-30 \%, 30 \%-70 \%$. High strength at the dosage of nepheline sludge and ash of $30 \%$ and $70 \%$ is due to the fact that nepheline sludge plays the role of an activator of ion exchange reactions and enhances the astringent properties of ash. When the active part of the ash interacts with the calcium components of the nepheline sludge, the formation of strong crystalline structural components occurs. The relation of nepheline sludge and ash of $30 \%-70 \%$, respectively, is optimal, because during the process of ion exchange all the nepheline sludge and ash particles interacted with each other, which is confirmed by high strength characteristics. When the ratio of nepheline sludge and ash is $70 \%-30 \%$, respectively, a strong crystalline lattice based on nepheline sludge is formed, while the ash in the composition of this mixture acts as a bulk filler. The material corresponds to the marks M30-M60 according to state standard $23558-94$. 
2. The graphs of fig. 2 shows the dependence of water absorption on the ash dosage and time of structure formation. Water absorption of samples value from 1.89 to $26.34 \%$. Water absorption on the graphs decreases depending on the time of structure formation, this confirms that the mixture of ash with nepheline sludge is a slow-hardening material. Structure that meets all physic-mechanical criteria is formed not less than 21 days after the samples were made.

3. The graphs of fig. 3 shows the dependence of the elastic modulus of water-saturated samples on the ash dosage and structure formation time, the elastic modulus value from 84.57 to $183 \mathrm{MPa}$, and with the optimal dosage of ash and nepheline sludge $(70 \%-30 \%)$, respectively, reaches $183 \mathrm{MPa}$. This meets the requirements of state standard $23558-94$.

4. The proposed material on the basis of ash obtained from the incineration of sewage sludge, reinforced by nepheline sludge, is suitable in its physical and mechanical characteristics for use in road construction. Indicators of strength, water absorption and modulus of elasticity at optimal dosages of the mixture of nepheline sludge and ash correspond to state standard $23558-94$.

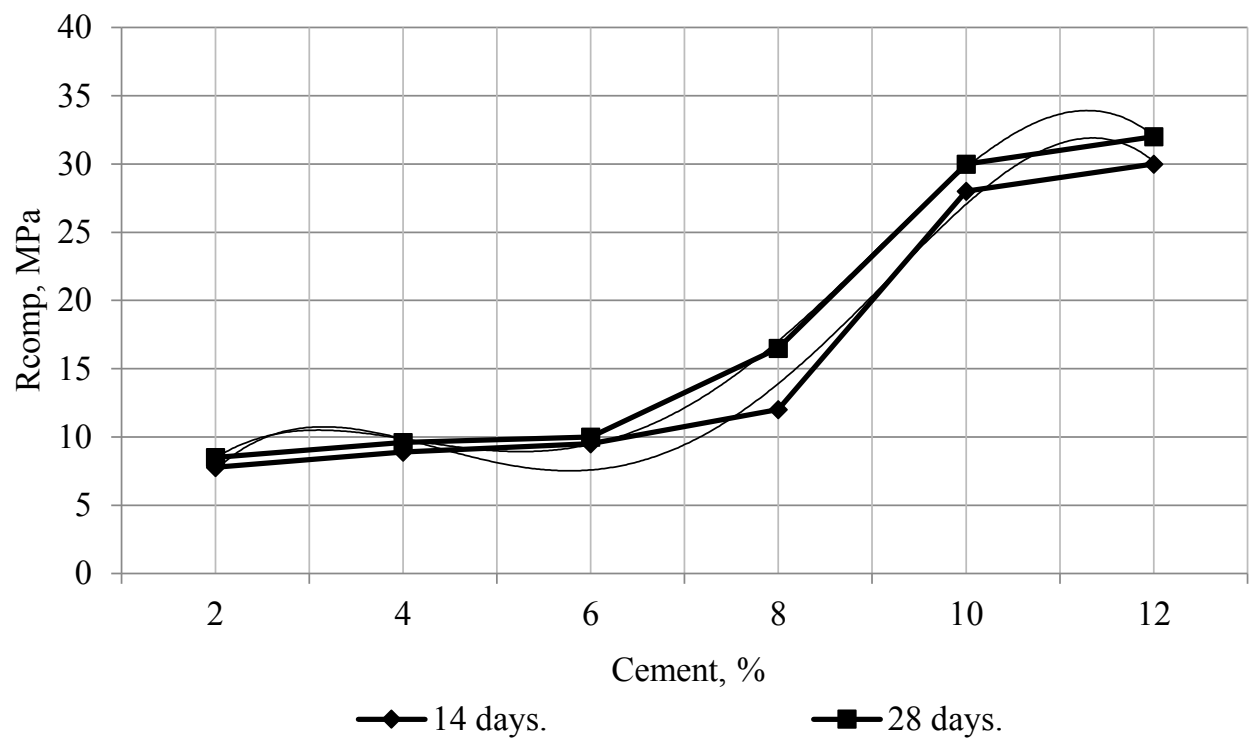

Fig. 4. Graphic dependence of the ultimate strength in compression of samples from ashes reinforced with cement, on the dosages of cement at different periods of their structure formation

The regression equations for the experimental curves are given below:

Structure formation time is 14 days.

$\mathrm{R}_{\text {compr }}=-0.624 \times 4+8.4342 \times 3-37.286 \times 2+64.456 \mathrm{x}-27,392 ; \mathrm{R}^{2}=0.9821$

Structure formation time is 28 days.

$\mathrm{R}_{\text {compr }}=-0.5271 \times 4+6.9042 \times 3-29.16 \times 2+48.48 \mathrm{x}-17.25 ; \mathrm{R}^{2}=0.9987$ 


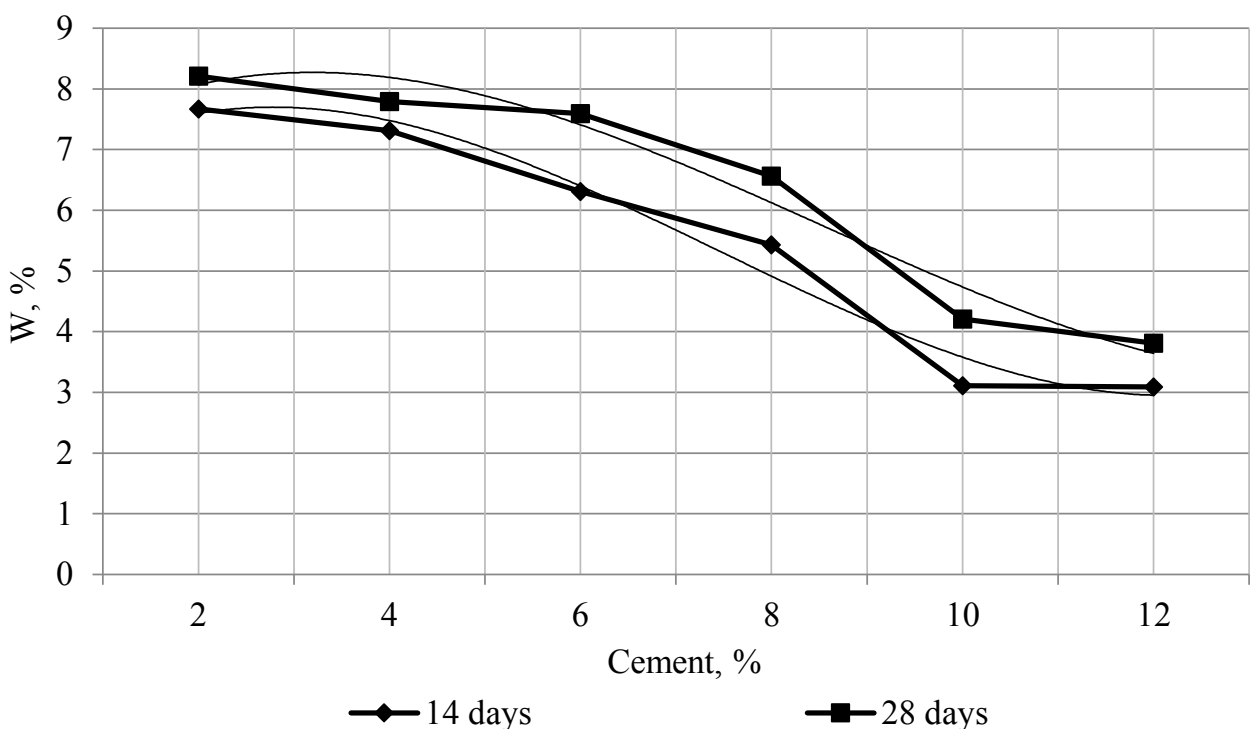

Fig. 5. Graph of water absorption of samples from ashes, reinforced with cement, on the dosages of cement at different periods of structure formation

The regression equation for the experimental curves is shown below:

Structure formation time is 14 days

$\mathrm{W}=0.0928 \times 3-1.0381 \times 2+2.3491 \mathrm{x}+6.19 ; \mathrm{R}^{2}=0.9728$

Structure formation time is 28 days

$\mathrm{W}=0.0665 \mathrm{x} 3-0.8498 \mathrm{x} 2+2.2051 \mathrm{x}+6.64 ; \mathrm{R}^{2}=0.961$

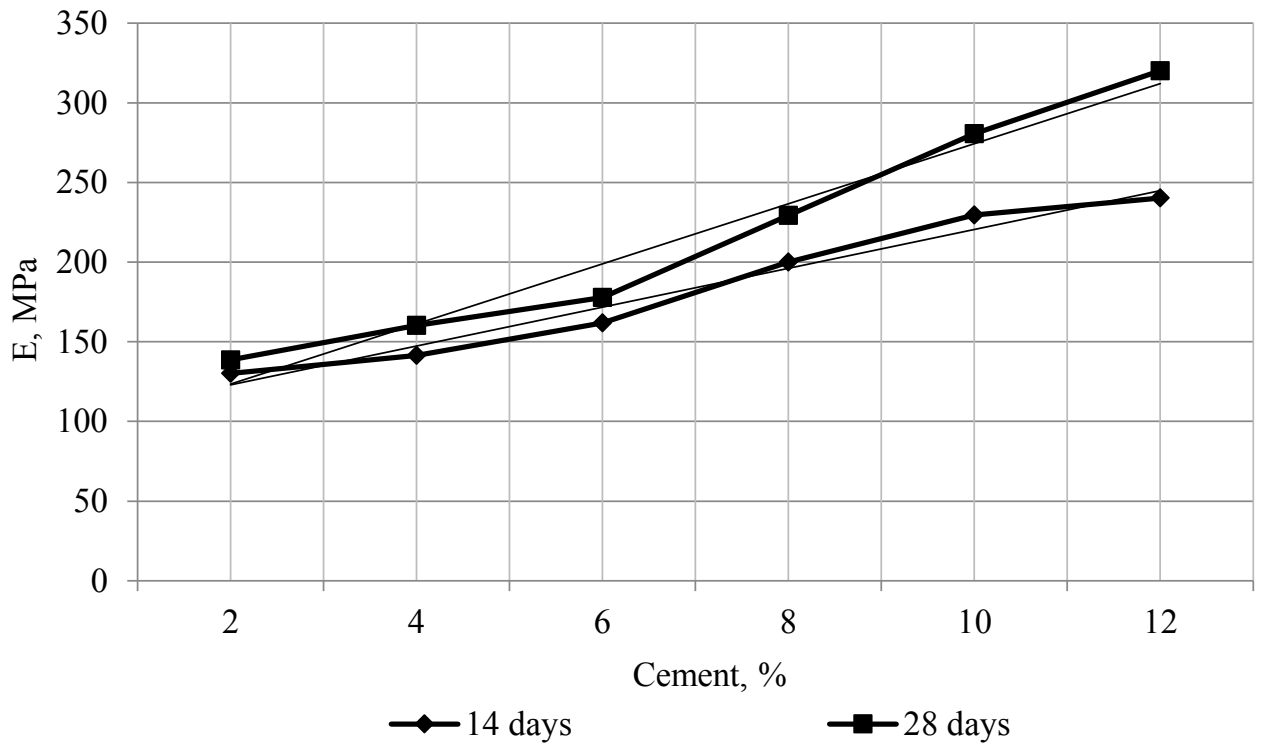

Fig. 6. Graph of the modulus of elasticity of samples from ashes reinforced with cement, on the dosages of cement at different periods of their structure formation

The regression equation for the experimental curves is shown below:

Structure formation time 14 days $-\mathrm{E}=24.381 \mathrm{x}+98.569 ; \mathrm{R}^{2}=0.9716$

Structure formation time 28 days $-\mathrm{E}=37.707 \mathrm{x}+85.779 ; \mathrm{R}^{2}=0.9674$ 


\subsection{Analysis of the study of the physical and mechanical properties of ash samples mixed with cement}

1. The graph of Fig. 4 shows the dependence of the compressive strength of watersaturated samples on the dosage of cement and the time of structure formation. The resulting material has a strength of from 7.78 to $32.51 \mathrm{MPa}$. The sharp increase in strength with an increase in cement dosage of more than $10 \%$ is due to a sufficient amount of activator for the formation of a solid structure. When cement dosages are from 2 to $12 \%$, the material corresponds to the grades M70-M100 according to state standard $23558-94$.

2. The graphs of fig. 5 shows the dependence of water absorption on the dosage of cement and the time of structure formation. Water absorption of samples ranges from 2 to $8.5 \%$. Water absorption on the graphs decreases depending on the increase of the cement content in the mixture.

3. In the graphs of fig. 6 shows the dependence of the elastic modulus of water-saturated samples on the dosage of cement and the time of structure formation, the value of the elastic modulus is changing from 140 to $340 \mathrm{MPa}$, which corresponds to the requirements of state standard $23558-94$.

4. The graphs of fig. 6 shows the dependence of the elastic modulus of water-saturated samples on the dosage of cement and the time of their structure formation, the value of the elastic modulus is changing from 140 to $340 \mathrm{MPa}$, which corresponds to the requirements of state standard $23558-94$.

\section{Conclusion}

The results of the study of mixtures of ash with mineral binders, such as nepheline sludge and cement show that the obtained materials have high strength and elastic modulus, they can be attributed to strength marks from M20 to M100. According to the results of the study, the physical and mechanical parameters of the experimental mixture are directly dependent on the percentage of nepheline sludge (or cement) in the structure.

It was experimentally confirmed that the activation of ash passes with calcium components of mineral binders with the formation of strong crystalline structural components.

In the course of the experiment, results confirming that the active properties of fine particles of silica and other ash minerals are highly ion exchangeable and form a strong ionic crystal lattice were obtained.

It can be said with confidence that the optimal indicators of the dosages of the binders were obtained. For a mixture of ash and nepheline sludge, the optimum dosage is $70 \%$ of ash and $30 \%$ of nepheline sludge, using the mixture (ash and cement), the required strength index is achieved at $2 \%$ cement.

When determining the strength characteristics of the experimental samples, the following values were revealed: the compressive strength of the samples for the mixture of ash and nepheline sludge is changing from 0.9 to $6.01 \mathrm{MPa}$, for the mixture of ash and cement from 7.78 to $32.51 \mathrm{MPa}$. The modulus of elasticity is switching from 60.52 to 184.16 $\mathrm{MPa}$ for a mixture of ash and nepheline sludge and from 130 to $320 \mathrm{MPa}$, the modulus of elasticity for a mixture of ash and cement, respectively. During the experiments, the rate of water absorption was also determined, it varies from 3.81 to $10 \%$ for a mixture of ash and cement and from 1.09 to $26.34 \%$ for a mixture of ash and nepheline sludge.

It can be concluded that the optimal dosages of the resulting mixture should take into account both laboratory, that is, experimental (compressive strength, elastic modulus and 
water absorption) and economic indicators (material price, delivery cost, storage cost) of mixtures.

It can be noted that the use of a mixture of ash and various binders leads to significant savings in material resources compared with the use of materials currently used according to the existing State Standards in the process of road construction.

The building material being developed (ash mixed with binders (nepheline sludge, cement)) can successfully replace similar building material in road construction technology, since this mixture in optimal dosages is more advantageous in the process of using both from the point of view of physical and mechanical and in terms of economic indicators.

\section{References}

1. I. V. Mescheryakov, Modern scientific research and innovation, 10 (2012)

2. V. M. Beskrovny, Application of nepheline sludge for the construction of the foundations of highways in Siberia (1983)

3. U.I. Prikhodko, Scientific community of students of the XXI century: collection of articles based on the materials of the XXVI international student scientific-practical conference, 11(26)

4. Gabriel Borowski, Polish Journal of Environmental Studies, 24(5), 1889 (2015)

5. Jiang-shan Li, Zhen Chen, Qiming Wang, Le Fang, Qiang Xue C.R. Cheeseman, Shane Donatello, Lei Liu, Chi Sun Poon, Waste Management, 74, 404 (2018)

6. O.A. Johnson, M. Napiah and I. Kamaruddin, Research Journal of Applied Sciences, Engineering and Technology, 8(4), 565 (2014)

7. O.V. Zubova, V.V. Siletskiy, A.P. Kozlov, K.V. Kuznetsov, Bulletin of the St. Petersburg Forestry Academy, 187 (2018)

8. O. V. Zubova, Investigation of the influence of the granulometric composition of soils on the strength of the zoological soil mixture treated with cement, Proceedings of BSTU, 118 (2012)

9. Antonio José Tenza-Abril, José Miguel Saval, Artemio Cuenca Using Sewage-Sludge Ash as Filler in Bituminous Mixes, Journal of Materials in Civil Engineering, 04014141 (2015)

10. O.V. Zubova, Proceedings of the St. Petersburg Forestry Academy, 172, 92 (2005)

11. Crushed stone-gravel-sand mixtures and soils treated with inorganic binders for road and airfield construction state standard, 23558-94 